\title{
On the Psychology of Religion: The Role of Personal Uncertainty in Religious Worldview Defense
}

\author{
Kees van den Bos, Jitse van Ameijde, and Hein van Gorp \\ Utrecht University
}

\begin{abstract}
In the present article, we examine the basic and applied aspects of the social psychology of religious worldview defense; that is, how people react in terms of negative affective reactions toward extremely antireligious statements that threaten their religious beliefs and/or may violate their views of how one should communicate about religious issues. An Internet study $(N=$ $1,529)$ and a laboratory experiment $(N=151)$ provide evidence for the hypothesis that salience of personal uncertainty concerns may lead people to react with more negative affective reactions toward extremely negative statements about religion, particularly when people are inclined to think of personal uncertainty as an emotionally threatening experience and when they are strongly religious. Implications for the psychology of religion and the social psychology of uncertainty and worldview defense are discussed.
\end{abstract}

What men really want is not knowledge but certainty. Bertrand Russell

I believe myself that his whole life was a search for God, or, for those who prefer less personal terms, for absolute certainty.

Katharina Tait (daughter of Bertrand Russell)

The above-mentioned famous quote by Bertrand Russell (nowadays to be found on numerous Web sites; see, e.g., http://creatingminds.org/quotes/certainty.htm) and the statement by his daughter writing of her father (cited in Towler, 1984, p. 100) highlight the issues we focus on in this article: the need for certainty and how this may influence the psychology of religious beliefs. More specifically, by means of an Internet study (including more than 1,500 respondents) and a more controlled laboratory experiment we examine both the basic and applied aspects of the social psychology of religious worldview defense; that is, how people react in terms of negative affective reactions toward extremely antireligious statements that threaten their religious beliefs and/or that may violate their views of how one should communicate about religious issues. In our two studies, we test the hypothesis that salience of personal uncertainty concerns (Van den Bos, 2001; Van den Bos, Poortvliet, Maas, Miedema, \& Van

Correspondence should be addressed to Kees van den Bos, Department of Social and Organizational Psychology, Utrecht University, Heidelberglaan 1,3584 CS Utrecht, the Netherlands. E-mail: k.vandenbos@ fss.uu.nl den Ham, 2005) as well as individual differences in emotional uncertainty (Greco \& Roger, 2001; Van den Bos, Euwema, Poortvliet, \& Maas, in press) and strength of religiousness may moderate religious worldview defense reactions. We shortly introduce the relationship between concerns of personal uncertainty, 9/11, and worldview defense. After this, we lay out the aims and hypotheses of the studies presented here.

\section{PERSONAL UNCERTAINTY AND 9/11}

One of the things the terrorist attacks in the United States on September 11, 2001 marked is that these alarming events constituted the beginning of a global increase in attention to issues of security. Citizens, politicians, journalists, and scientists, including social psychologists (e.g., Fischer, Greitemeyer, Kastenmüller, Jonas, \& Frey, 2006; Pyszczynski, Solomon, \& Greenberg, 2003; Skitka, Bauman, \& Mullen, 2004), quite rightfully started to worry about issues of security and related topics. Security is a broad construct, we argue, and involves not only concerns about physical danger and assault but also entails psychological concerns about safety and uncertainty (e.g., Murray, Holmes, $\&$ Collins, 2005). September 11th also constituted a clash between worldviews of Islamic extremists and American beliefs, including a conflict between different religious worldviews. Since the attacks, the issue of how to deal with different worldviews and how to respond to negative or criti- 
cizing statements about one's own worldview has been of special relevance and has kept people all over the world busy. In the present article, we focus on the social psychological issue of how concerns of personal uncertainty may influence people's reactions to statements that constitute a threat to their worldviews.

As far as we know, worldview defense reactions to extremely negative statements about religion have not been examined before, yet how to deal with these kinds of statements that may threaten the worldviews of most people may constitute one of the challenges human mankind faces after 9/11. Here, we study this issue by building and extending on the literatures on worldview defense (e.g., Pyszczynski et al., 2003), uncertainty (e.g., Hogg, 2004), and uncertainty and worldview defense (e.g., Martin, 1999; McGregor, Zanna, Holmes, \& Spencer, 2001; Van den Bos, 2001; Van den Bos et al., 2005; Van den Bos, Euwema, et al., in press). Insights that may follow from the studies we present here may be relevant for basic aspects of these literatures and, by studying the process by which people react to extreme statements about religion, may further scientific knowledge about psychology and religion (e.g., Batson \& Stocks, 2004; Baumeister, 2002; Hinde, 1999; Salsman, Brown, Brechting, \& Carlson, 2005; Smith, McCullough, \& Poll, 2003; Towler, 1984). Also, because religious worldview defense may be an important issue for how people interact with and respond to each other in the world, especially in the world as we know it after 9/11, examining this issue may be important for both the basic and applied aspects of social psychology.

\section{PERSONAL UNCERTAINTY AND WORLDVIEW DEFENSE}

We base our research on the assumption that managing uncertainty is an important motive that often drives people's reactions and behaviors (e.g., Hogg, 2000, 2001, 2004, 2005). There are different types of uncertainties that people can encounter (Van den Bos \& Lind, 2002), but a crucial, and perhaps the most important type, is personal uncertainty, the experience that is the result of people being uncertain about themselves (see, e.g., Van den Bos, 2001). On the basis of the above-reviewed literature, we propose that people want to protect themselves from being in or thinking of situations in which they were uncertain about themselves. One way in which people can do this is by adhering to their cultural norms and values (e.g., Van den Bos et al., 2005). Experiences that are supportive of people's cultural worldviews lead people to be less uncertain about themselves or to be able to better tolerate the uncertainty (e.g., Van den Bos, Heuven, Burger, \& Fernández Van Veldhuizen, 2006). As a result, uncertainty management theories predict that people who are uncertain about themselves or who have been reminded about their personal uncertainties will react very positively toward worldview-supportive experiences (e.g., Van den Bos, 2001). In contrast, experiences that threaten or impinge on people's worldviews do not help people to cope with their uncertainties, and hence people will respond very negatively toward these worldview-threatening experiences (e.g., Van den Bos et al., 2005).

Results of different uncertainty management studies are in accordance with the above-described predictions (e.g., Hogg, 2004; McGregor et al., 2001; Van den Bos et al., 2005; Van den Bos, Euwema, et al., in press). For example, Van den Bos, Euwema, et al. (2006, Study 1) showed that asking (as opposed to not asking) people to think about their uncertainties may lead them to react more negatively toward a person who has been communicating negative things about their home country. Uncertainty salience may also lead people with negative attitudes toward homeless people to objectively distance themselves more from belongings and materials associated with homeless individuals (Van den Bos, Euwema, et al., 2006, Study 3). Furthermore, building on the observation that praise of students' own university constitutes a bolstering of their cultural worldviews, whereas criticism of the university represents a violation of participants' worldviews (Dechesne, Janssen, \& Van Knippenberg, 2000), Van den Bos et al. (2005, Experiments 3 and 4) hypothesized and showed that when university students have been reminded about their personal uncertainties they will react more negatively toward information that is unfavorable about their university.

Moreover, in all five experiments presented in the Van den Bos et al. (2005) article, personal uncertainty was a more important moderator of cultural worldview defense reactions than another conceptually important determinant, namely salience of mortality concerns (see Greenberg, Solomon, \& Pyszczynski, 1997; Pyszczynski, Greenberg, \& Solomon, 1999; Solomon, Greenberg, \& Pyszczynski, 1991). The findings of Van den Bos et al. also indicate that effects of mortality salience manipulations may be driven by thoughts about personal uncertainty. These findings thus suggest that, at least sometimes, models of uncertainty management (e.g., Van den Bos \& Lind, 2002; see also Martin, 1999; McGregor et al., 2001) may better explain people's reactions to cultural worldview defense reactions than viable and important alternative accounts (such as terror management theory).

Other studies also provide supportive evidence for predictions by related uncertainty management models. Hofstede (2001), for example, showed that compared with people who are low in uncertainty avoidance, those high in uncertainty avoidance are more conservative, less tolerant of diversity, less open to new experiences and alternative lifestyles, want immigrants to be sent back to their countries of origin, and reject people from other races as their neighbors. McGregor and colleagues (e.g., McGregor, 2004; McGregor et al., 2001; McGregor \& Marigold, 2003) revealed that people who are made uncertain about themselves react more defensively toward events that threaten their cultural worldview and that people do so because in this way they attempt to re- 
store their sense of self (namely becoming persons who can be certain about themselves; see also Martin, 1999). Related to this, Hogg $(2000,2004,2005)$ showed that extreme self-uncertainty can motivate people to believe more in ideological belief systems related to orthodoxy, hierarchy, and extremism (see also Towler, 1984).

\section{PERSONAL UNCERTAINTY AND RELIGIOUS WORLDVIEW DEFENSE}

As mentioned before, one of the things 9/11 stood for was a clash between different religious worldviews, and it could be argued that a challenge for people living in the world after 9/11 is how to respond to critical statements about one's own worldview. In the current article, we use the insights we can derive from the above-reviewed uncertainty management work to better understand how people react to extremely negative statements about religion. Although a lot of work has been done on uncertainty and worldview defense (e.g., Hogg, 2004; McGregor et al., 2001; Van den Bos et al., 2005; Van den Bos, Euwema, et al., in press) as well as on uncertainty and religion (e.g., Towler, 1984), we do not know of studies that examined the potential moderating influence of personal uncertainty on reactions toward extreme antireligious statements that threaten people's religious beliefs and/or that may violate their views of how one should communicate about religious issues. On the basis of the above-reviewed theory and research on uncertainty and worldview defense (e.g., Hogg, 2004; McGregor et al., 2001; Van den Bos et al., 2005; Van den Bos, Euwema, et al., in press) we can confidently predict that salience of personal uncertainty concerns will lead people to exhibit with more negative affective reactions toward extremely negative statements about religion (Studies 1 and 2), especially when they are inclined to think of personal uncertainty as an emotionally threatening experience (Study 1) and when they are strongly religious (Study 2). This hypothesis is tested in our two studies, after which we discuss the theoretical and applied implications of the line of reasoning and research presented here.

\section{STUDY 1}

In Study 1, we tested whether people high in emotional uncertainty (see, e.g., Van den Bos et al., 2003) and whose personal uncertainty concerns have been made salient (see, e.g., Van den Bos, 2001) would react with more negative affective reactions toward extremely negative statements about religion. We tested this hypothesis by means of an Internet study in which more than 1,500 Dutch respondents participated in a study on psychology and religion. Respondents were readers of a Dutch psychology magazine that is respectful about other religious worldviews and how one should communicate about religious issues. In the study, we first measured re- spondents' scores on the Emotional Uncertainty Scale of Greco and Roger (2001). After this, we made respondents' personal uncertainty concerns salient by using the method developed by Van den Bos (2001; Van den Bos et al., 2005). This was followed by asking respondents to read an article in which a person who was extremely negative about religious issues was interviewed. After this, we assessed how angry respondents felt about the article.

\section{Method}

Respondents. Between August and October 2005, a total of 1,529 people responded to an invitation in Psychologie Magazine, a popular Dutch magazine that reviews and applies psychological insights and theories, to participate in an Internet study on psychology and religion. Three hundred thirty-nine men and 1,190 women participated in the study. Mean age of the respondents was 34.91 years $(S D=12.93)$, with the oldest respondent being 93 years old and the youngest respondent being 14 years old. Most respondents were 24 years old, and the median age was 33 years. Seven percent of the respondents had completed a lower form of education, $22 \%$ had completed a middle-level form of education, $49 \%$ had completed a higher form of education, and $23 \%$ had completed a university degree.

Measures. The questionnaire that respondents completed first measured respondents' emotional reactions to experiencing uncertainty in their personal lives. To this end, respondents answered the Emotional Uncertainty Scale of Greco and Roger (2001). The items in this scale ask respondents to indicate on a 7-point Likert-type scale, ranging from 1 (strongly disagree) to 7 (strongly agree), the extent to which they agree with statements such as "I get worried when a situation is uncertain" and "Facing uncertainty is a nerve wracking experience." Respondents' answers to the 15 items of the scale were averaged to form a reliable index of their emotional reactions to personal uncertainty $(\alpha=.92)$.

After completing these questions and after answering some filler items that were unrelated to the present study, the salience manipulation was induced. Following earlier uncertainty management studies (Van den Bos, 2001; Van den Bos et al., 2005), respondents in the uncertainty salient condition were asked to respond to two open-ended questions concerning their thoughts and feelings about their being uncertain: (a) "Please briefly describe the emotions that the thought of your being uncertain arouses in you" and (b) "Please write down, as specifically as you can, what you think physically will happen to you as you feel uncertain.” These questions were not posed to the respondents in the condition in which uncertainty was not made salient.

After this, all respondents completed the Positive and Negative Affect Schedule (PANAS; Watson, Clark, \& Tellegen, 1988), on which they reported on 20 items about how they felt at the moment. The items in this scale ask re- 
spondents to indicate on a 5-point Likert-type scale, ranging from 1 (not at all) to 5 (very strongly), whether they experience such things as "excitement" and "guilt." Following previous uncertainty salience experiments (e.g., Van den Bos, 2001; Van den Bos et al., 2005), the PANAS was included as a filler task and to determine whether the salience manipulation engendered positive and negative affect. The PANAS consists of two 10-item subsets (Watson et al., 1988), one measuring positive affect (PA) and one measuring negative affect (NA), and both subsets were averaged to form reliable scales ( $\alpha s=.84$ and .89 , respectively).

We then assessed respondents' anger toward antireligious stimulus materials by asking respondents to read and respond to an article presented in the questionnaire, in which the following opinion was stated:

I think religion is the biggest illusion of human mankind. I have been raised as an atheist and I am completely satisfied with that. I do not get how people can be so stupid that they want to restrict their lives by adhering to hopelessly outdated religious ideas; ideas that since the days of the first great philosophers have been proven to be wrong. Religion shows how narrow-minded people can think and how they can stick to old texts of which the origins are unknown and that are painfully wrong. In this modern era of technological progress, religion is of no use. I can understand why in ancient ages people were religious. After all, people did not understand the world back then and religion then gave meaning to inexplicable phenomena. Now that we can understand, predict, and alter natural phenomena (thanks to science and technology), religion has no purpose whatsoever. Religion is only the cause of much misunderstanding and for many problems and wars in this world. The same religion that tells people to respect each other is used to slaughter people and to enforce obedience to authority. The basic fact that there are so many different religions should be some indication that religious people are wrong. Furthermore, I think that those people who state that God has put fossils on this world to test our faith should be put away in an institution for stubborn stupidity. The Bible and the Koran should be burned to ashes. Religious people can be summarized as follows: stupid, bigoted, pathetic, deranged, and narrow minded.

Respondents' reactions of anger toward this article were measured by asking respondents to indicate on a 7-point Likert-type scale, ranging from 1 (strongly disagree) to 7 (strongly agree), the extent to which they agreed with the statement: "The article makes me angry." At the end of the survey, respondents were debriefed about the purposes of our study.

\section{Results}

Overview of data analyses. We used hierarchical regression to test for the interaction effect that we predicted between the centered (Aiken \& West, 1991) emotional uncertainty variable and the effect-coded (Cohen, Cohen, West, \&
Aiken, 2003) manipulation of uncertainty salience. In the first step of these analyses, we controlled for differences in the demographic variables of our Internet study (gender, age, and education), and in the second step we tested for the main and interaction effects of emotional uncertainty and uncertainty salience. Examination of the data for outliers in these analyses (with Cook's Distance measure; see Cook, 1977; see also Cohen, Cohen, West, \& Aiken, 2003, pp. 202-204) revealed that 3 respondents could be identified as outliers. These 3 (out of 1,529) respondents were not included in our regression analyses. ${ }^{1}$

PANAS. Regression analyses on the positive and negative subsets of the PANAS showed no significant main or interaction effects of our independent variables on both PA and NA. Overall means of PA and NA were $2.83(S D=0.71)$ and $1.47(S D=0.59)$, respectively.

Anger toward article. Regression analysis on respondents' anger toward the antireligious article yielded a significant main effect of emotional uncertainty, $\beta=.60, p<.02$, and a significant Emotional Uncertainty $\times$ Uncertainty Salience, $\beta=-.49, p<.04$. Figure 1 shows these effects, plotting anger scores of respondents with relatively low levels of emotional uncertainty (scoring below the median of 3.20 of the emotional uncertainty scale) and respondents with relatively high levels of emotional uncertainty (scoring on or above the median) in the uncertainty salient and nonsalient conditions. The main effect of uncertainty salience was not significant, $\beta=-.00, p>.97$. The main effect of emotional uncertainty indicated that respondents with higher levels of emotional uncertainty reacted with more anger toward the antireligious article. Furthermore, as predicted, the interaction effect showed that respondents in the uncertainty salient condition were influenced more strongly by their emotional uncertainty style, $\beta=.17, p<.001$, than were those in the uncertainty nonsalient condition, $\beta=.13, p<.001$.

In addition, it can be noted here that respondents with relatively high levels of emotional uncertainty (see Figure 1) reacted with significantly more anger when uncertainty had been salient than when uncertainty had not been made salient, $F(1,1524)=5.88, p<.02$, whereas respondents with comparatively low levels of emotional uncertainty did not react differently as a function of the uncertainty salience manipulation, $F(1,1524)=0.05, p>.81$.

\section{DISCUSSION}

The findings of Study 1 indicate that people for whom personal uncertainty is a salient concern and who are high in emotional uncertainty may react with more anger toward

\footnotetext{
${ }^{1}$ We thank an anonymous reviewer for suggesting this procedure to us.
} 


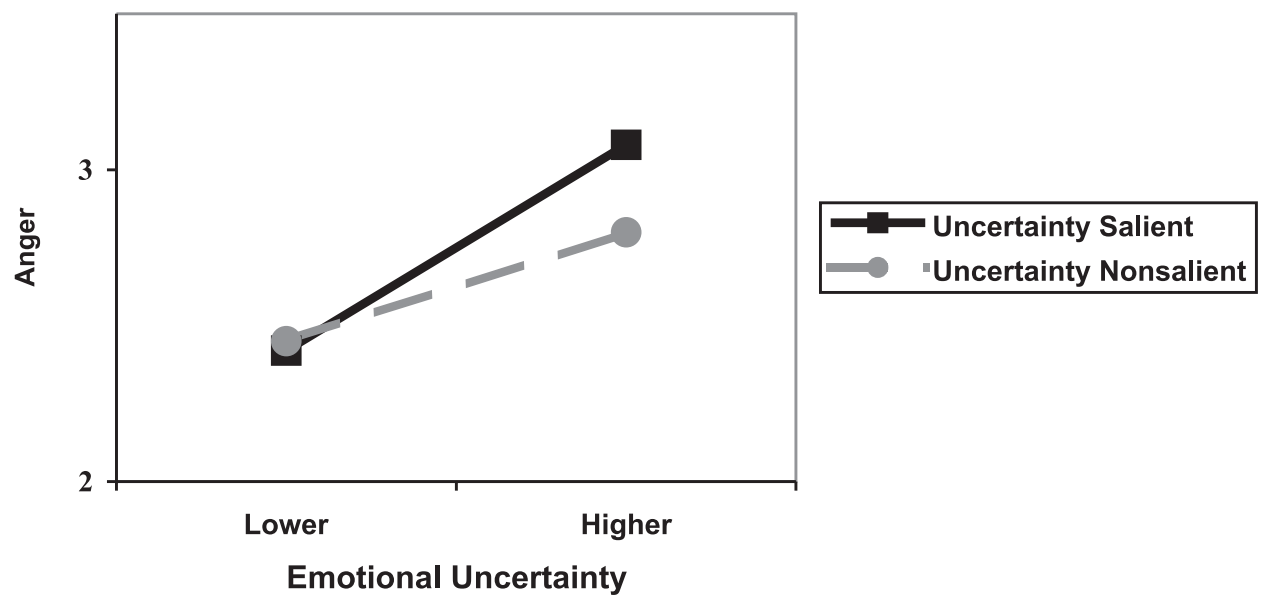

FIGURE 1 Anger toward antireligious article as a function of emotional uncertainty and uncertainty salience (Study 1).

extremely negative statements about religion. More specifically, building and extending on the emotional uncertainty work by Greco and Roger (2001), our findings suggest that reminding people of their personal uncertainties does not yield a strong main effect on people's reactions of religious worldview defense but that the effect of personal uncertainty is moderated by the extent to which people experience uncertainty to be a threatening event. Thus, an important precondition for the impact of uncertainty salience on religious reactions may be that it should be perceived as an emotionally threatening experience (Greco \& Roger, 2001). If uncertainty is not considered a threatening event, then reminding people of their personal uncertainties may not have strong or significant effects on reactions of religious worldview defense.

\section{STUDY 2}

In Study 2, we wanted to extend these findings by assessing under more controlled conditions a multi-item measure of people's religious worldview defense reactions by using a somewhat extended uncertainty salience manipulation and by incorporating another relevant individual difference variable in our empirical research: Study 2 was a laboratory experiment in which participants completed three ostensibly unrelated studies. In the first study, we assessed the strength with which participants were religious. In the second study, uncertainty salience was manipulated. Finally, in the third study, we solicited participants' anger and two other negative affective reactions toward the antireligious materials of Study 1.

\section{Method}

Participants and design. One hundred fifty-one students (38 men and 113 women) at Utrecht University took part in the study and were paid or received course credit for their participation. Mean age of the participants was 21.10 years $(S D=3.66)$. The youngest participant was 17 years old and the oldest participant was 53 years. Most participants were 19 years old, and the median age was 20 years.

Experimental procedure. Students at Utrecht University were invited to our laboratory to participate in various studies. On arrival at the laboratory, participants were led to separate cubicles, each of which contained a computer with a monitor and a keyboard. Next to the monitor, participants found pieces of paper and a pencil. The computers were used to present the stimulus information and to measure individual differences in strength of religiousness as well as participants' scores on the PANAS scales and their negative affective reactions toward the antireligious article. Participants took part in our study after participating in a short study that was unrelated to our study and before taking part in other studies.

Our experiment was presented to the participants as three separate studies. In the first study, participants completed six items that assessed their strength of religiousness. The items asked participants to indicate on a 7-point Likert-type scale, ranging from 1 (not at all) to 7 (very much), their opinions about statements such as "To what degree do you see yourself as a religious person?" and "To what degree does religion play an important role in your life?" Respondents' answers were averaged to form a reliable index of their religiousness $(\beta=.94)$.

In the second study, uncertainty salience was manipulated. Building and extending on Study 1, respondents in the uncertainty salient condition were asked to respond to three open-ended questions concerning their thoughts and feelings about their being uncertain. The first two questions were the same as in Study 1, and the third question asked participants the following: "Please briefly describe in what kind of situations you experience a lot of personal uncertainty." Participants in the uncertainty nonsalient condition were asked three questions that were highly similar in format but that did 


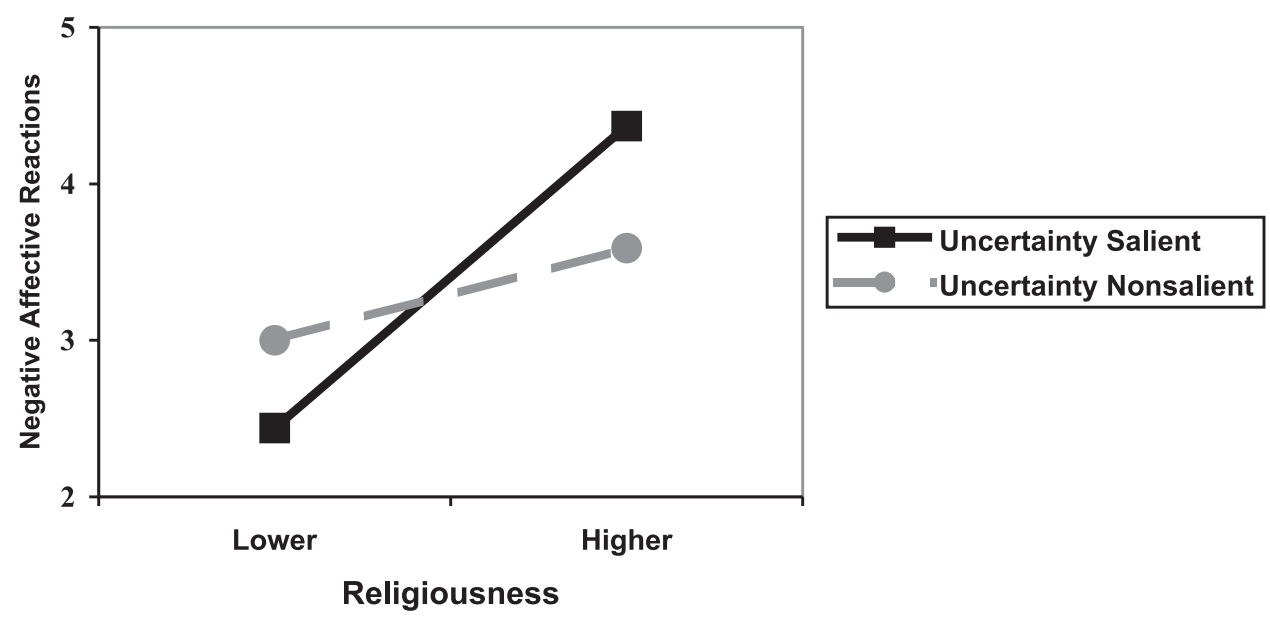

FIGURE 2 Negative affective reactions toward antireligious article as a function of religiousness and uncertainty salience (Study 2).

not remind participants about their uncertainties (Van den Bos, 2001; Van den Bos et al., 2005). That is, building on earlier uncertainty management research (e.g., Van den Bos, 2001; Van den Bos et al., 2005), these participants were asked to write down on a piece of paper next to the computer their answers to the following questions: (a) "Please briefly describe the emotions that the thought of you watching TV arouses in you," (b) "Please write down, as specifically as you can, what you think physically will happen to you as you watch TV," and (c) "Please briefly describe in what kind of situations you like to watch TV." After this, all participants completed the PANAS, with both the positive and negative subsets again yielding reliable scales $(\beta \mathrm{s}=.84$ and .88 , respectively).

In the third study, participants read the same antireligious article as in Study 1, after which they were asked to indicate on a 7-point Likert-type scale, ranging from 1 (strongly disagree) to 7 (strongly agree), the extent to which they agreed with the following three statements: "The article makes me angry," "The article irritates me," and "The article makes me feel disappointed." Participants' answers to the three items were strongly correlated, $r \mathrm{~s}>.66, p \mathrm{~s}<.001$, and were averaged to yield a reliable scale of participants' negative affective reactions toward the article $(\beta=.88)$. When the participants had answered these questions and had completed the other studies in which they would participate, they were thoroughly debriefed and were paid or received course credit for their participation. None of the participants objected to the procedure we used in our experiment or the stimulus materials we presented in the study.

\section{Results}

Overview of data analyses. Similar to Study 1, we used hierarchical regression to test for the predicted interaction effect between the centered religiousness variable and the effect-coded manipulation of uncertainty salience. In our analyses we controlled for differences in the demographic variables of Study 2 (gender and age). In Study 2, no outliers had to be removed from the data analyses.

PANAS. Regression analysis on the positive subset of the PANAS showed no significant main or interaction effects. Overall mean was $3.54(S D=0.85)$. Regression analysis on the negative subset showed a main effect of the uncertainty salience manipulation only, $\beta=.19, p<.03$, indicating that participants in the uncertainty salient condition showed higher levels of NA $(M=1.86, S D=0.71)$ than those in the condition in which uncertainty was not salient $(M=1.59, S D$ $=0.60) .{ }^{2}$ In the General Discussion, we discuss the implications of these findings.

Negative affective reactions toward article. Regression analysis on participants' negative affective reactions toward the antireligious article showed a significant main effect of religiousness, $\beta=.53, p<.001$, and a significant interaction effect between religiousness and uncertainty salience, $\beta=.18, p<.01$. Figure 2 shows these effects, plotting negative affective reactions of respondents with relatively low levels of religiousness (scoring on or below the median of 2.17 of the religiousness scale) and relatively high levels of religiousness (scoring above the median) in the uncertainty salient and nonsalient conditions. The main effect of uncertainty salience was not significant, $\beta=-.01, p>.86$. The main effect of religiousness indicated that respondents with higher levels of religiousness reacted with more anger toward the antireligious article. Moreover, as hypothesized, the interaction effect showed that participants in the uncertainty salient condition were influenced more strongly by

\footnotetext{
${ }^{2}$ After controlling for respondents' scores on the NA scale in an hierarchical regression analysis, the dependent variable of Study 2 (negative affect toward the antireligious article) still yielded a significant main effect of religiousness, $\beta=.54, p<.001$, as well as a significant interaction between religiousness and uncertainty salience, $\beta=.19, p<.01$.
} 
their strength of religiousness, $\beta=.66, p<.001$, than were those in condition where uncertainty was not salient, $\beta=.37$, $p<.01$.

It can also be noted here that participants with higher levels of religiousness (see Figure 2) showed significantly more negative affect when uncertainty was salient than when uncertainty was not salient, $F(1,145)=5.84, p<.02$, whereas participants with lower levels of religiousness did not show a statistically significant effect of the uncertainty salience manipulation, $F(1,145)=1.11, p>.29$.

\section{GENERAL DISCUSSION}

As hypothesized, findings of Study 2 show that particularly people whose personal uncertainties have been made salient and who hold strong religious beliefs may react with more negative affect toward extremely negative statements about religion. Taken together, the findings of the two studies presented here suggest that salience of personal uncertainty may lead people to react with more anger (Study 1) and with more general negative affective reactions (Study 2) toward antireligious statements, especially when they are inclined to think of personal uncertainty as an emotionally threatening experience (Study 1) and particularly when they are strongly religious (Study 2).

One implication of the current findings may be that religious beliefs and/or beliefs about how one should communicate about religious beliefs may serve as cultural worldviews. When these worldviews are threatened, for example by extreme negative statements about religion, then people may respond with negative affective reactions to these worldview threats. Furthermore, as the literature on uncertainty and worldview defense (e.g., Hogg, 2004; Martin, 1999; McGregor et al., 2001; Van den Bos, 2001; Van den Bos et al., 2005; Van den Bos, Euwema, et al., in press) and the psychology of religion (e.g., Batson \& Stocks, 2004; Baumeister, 2002; Hinde, 1999; Salsman et al., 2005; Smith et al., 2003; Towler, 1984) would predict, these religious worldview defense reactions are much stronger when salience of personal uncertainty are combined with high levels of emotional uncertainty (Study 1) as well as with high levels of religiousness (Study 2).

In our studies, we assumed that extremely negative statements about religion would violate the religious beliefs of most people or at least would go against their views of how one should communicate about religious issues. Debriefing interviews conducted in Study 2 and the findings reported in both Studies 1 and 2 are in accordance with this line of reasoning. Furthermore, a close inspection of the findings reported in Study 2 suggests that there was a tendency for participants with low levels of religiousness (see Figure 2) to react with less negative affect toward the antireligious article when uncertainty had been made salient than when uncertainty had not been made salient, $t(74)=-1.69, p<.05$ (one-tailed). Thus, among participants low in religious beliefs, and for whom the antireligious materials may not have violated but actually to some extent may have supported their worldviews, there was some evidence for less negative affect toward the antireligious statements when personal uncertainty had been made salient. Although this effect was not very strong and was not statistically significant when we tested the corresponding simple main effect (reported in the Results section), the pattern of results of Study 2 is in line with the literature on uncertainty and worldview defense (e.g., Van den Bos et al., 2005) and suggests that people who have been reminded about their personal uncertainties may not only react negatively toward statements that violate their religious worldviews (cf. people high in religiousness) but to some extent may also react more positively toward experiences that support their religious views (cf. people low in religiousness).

It should be noted here that the negative subset of the PANAS scales showed an unexpected main effect of uncertainty salience in Study 2. This said, our independent variables did not show interactive effects on the PANAS scales and controlling for the NA findings of Study 2 did not wipe out the effects on our worldview defense measures (see Footnote 2). This being said, an implication of the findings reported here is that clearly more research on the subtle yet intriguing effects of uncertainty concerns and related variables is warranted that pays appropriate attention to relevant moderators of the influence of personal uncertainty on religious worldview defense.

A relevant moderator in this respect may be the distinction between intrinsically and extrinsically religious orientations (see, e.g., Allport, 1959; Allport \& Ross, 1967; Fischer et al., 2006; Ryan, Rigby, \& King, 1993). Intrinsic religiousness is characterized by the striving for meaning and value that gives people a feeling of self-efficacy that may help them to cope with increased salience of terrorism, whereas extrinsically religious people may use religion primarily to protect the self and gain social standing (Fischer et al., 2006). Future research may reveal that intrinsic and extrinsic religiousness may instigate different uncertainty management processes and different responses to terrorism and other worldview threatening experiences. We hope the present article contributes to these future research attempts.

In closing, let us repeat that one of the challenges humans face following the terrible events of $9 / 11$ is how to achieve religious tolerance and how to communicate with each other about different views on religion. Partly stimulated by this observation, we started to examine the role that personal uncertainty may have in how people respond to statements that may threaten their religious worldviews. Of course, more research on these intriguing issues is important. The concept of the need for certainty, as described by Towler (1984) for example, may be important in this respect. Furthermore, intrinsic religious orientations have been suggested to help in coping with terrorism (Fischer et al., 2006), and the examination 
of other religious worldview threats than the one we studied here would be a valuable addition to the growing literature on the psychology of religion (e.g., Allport, 1959; Allport \& Ross, 1967; Batson \& Stocks, 2004; Baumeister, 2002; Fischer et al., 2006; Hinde, 1999; Ryan et al., 1993; Salsman et al., 2005; Smith et al., 2003). The research findings we present here suggest that the self-regulatory function that religion may have (e.g., Fischer et al., 2006) may be related to processes of uncertainty management. Finding evidence for this suggestion would indicate that we could paraphrase Bertrand Russell's famous quote with which we began our article in the following way: What men (and women) really want is not religion but certainty. We hope this may turn out be one way in which our research on the role of personal uncertainty in religious worldview defense may help to further the psychology of religion.

\section{ACKNOWLEDGMENTS}

We thank Jaap Ham, Allan Lind, and Marjolein Maas for their suggestions during the writing of this research project.

\section{REFERENCES}

Aiken, L. S., \& West, S. G. (1991). Multiple regression: Testing and interpreting interactions. Newbury Park, CA: Sage.

Allport, G. W. (1959). Religion and prejudice. Crane Review, 2, 1-10.

Allport, G. W., \& Ross, J. M. (1967). Personal religious orientation and prejudice. Journal of Personality and Social Psychology, 5, 432-443.

Batson, C. D., \& Stocks, E. L. (2004). Religion: Its core psychological functions. In J. Greenberg, S. L. Koole, \& T. Pyszczynski (Eds.), Handbook of experimental existential psychology (pp. 141-155). New York: Guilford Press.

Baumeister, R. F. (2002). Religion and psychology: Introduction to the special issue. Psychological Inquiry, 13, 165-167.

Cohen, J., Cohen, P., West, S. G., \& Aiken, L. S. (2003). Applied multiple regression/correlation analysis for the behavioral sciences (3rd ed.). Hillsdale, NJ: Lawrence Erlbaum Associates.

Cook, R. D. (1977). Detection of influential observations in linear regression. Technometrics, 19, 15-18.

Dechesne, M., Janssen, J., \& Van Knippenberg, A. (2000). Derogation and distancing as terror management strategies: The moderating role of need for closure and permeability of group boundaries. Journal of Personality and Social Psychology, 79, 923-932.

Fischer, P., Greitemeyer, T., Kastenmüller, A., Jonas, E., \& Frey, D. (2006). Coping with terrorism: The impact of increased salience of terrorism on mood and self-efficacy of intrinsically religious and nonreligious people. Personality and Social Psychology Bulletin, 32, 365-377.

Greco, V., \& Roger, D. (2001). Coping with uncertainty: The construction and validation of a new measure. Personality and Individual Differences, 31, 519-534.

Greenberg, J., Solomon, S., \& Pyszczynski, T. (1997). Terror management theory of self-esteem and cultural worldviews: Empirical assessments and conceptual refinements. In M. P. Zanna (Ed.), Advances in experimental social psychology (Vol. 29, pp. 61-139). New York: Academic Press.

Hinde, R. A. (1999). Why gods persist: A scientific approach to religion. London: Routledge.
Hofstede, G. (2001). Culture's consequences: Comparing values, behaviors, institutions, and organizations across nations (2nd ed.). Thousand Oaks, CA: Sage.

Hogg, M. A. (2000). Subjective uncertainty reduction through self-categorization: A motivational theory of social identity processes. In W. Stroebe \& M. Hewstone (Eds.), European review of social psychology (Vol. 11, pp. 223-255). Chichester, UK: Wiley.

Hogg, M. A. (2001). Self-categorization and subjective uncertainty resolution: Cognitive and motivational facets of social identity and group membership. In J. P. Forgas, K. D. Williams, \& L. Wheeler (Eds.), The social mind: Cognitive and motivational aspects of interpersonal behavior (pp. 323-349). New York: Cambridge University Press.

Hogg, M. A. (2004). Uncertainty and extremism: Identification with high entitativity groups under conditions of uncertainty. In V. Yzerbyt, C. M. Judd, \& O. Corneille (Eds.), The psychology of group perception: Perceived variability, entitativity, and essentialism (pp. 401-418). New York: Psychology Press.

Hogg, M. A. (2005). Uncertainty, social identity and ideology. In S. R. Thye \& E. J. Lawler (Eds.), Advances in group processes (Vol. 22, pp. 203-230). New York: Elsevier.

Martin, L. L. (1999). I-D compensation theory: Some implications of trying to satisfy immediate-return needs in a delayed-return culture. Psychological Inquiry, 10, 195-208.

McGregor, I. (2004). Zeal, identity, and meaning: Going to extremes to be oneself. In J. Greenberg, S. L. Koole, \& T. Pyszczynski (Eds.), Handbook of experimental existential psychology (pp. 182-199). New York: Guilford Press.

McGregor, I., \& Marigold, D. C. (2003). Defensive zeal and the uncertain self: What makes you so sure? Journal of Personality and Social Psychology, 85, 838-852.

McGregor, I., Zanna, M. P., Holmes, J. G., \& Spencer, S. J. (2001). Compensatory conviction in the face of personal uncertainty: Going to extremes and being oneself. Journal of Personality and Social Psychology, 80, $472-488$.

Murray, S. L., Holmes, J. G., \& Collins, N. L. (2005). The relational signature of felt security. Paper presented at the 2005 Conference of the Society of Experimental Social Psychology, San Diego, CA.

Pyszczynski, T. A., Greenberg, J., \& Solomon, S. (1999). A dual-process model of defense against conscious and unconscious death-related thoughts: An extension of terror management theory. Psychological Review, 106, 835-845.

Pyszczynski, T., Solomon, S., \& Greenberg, J. (2003). In the wake of 9/11: The psychology of terror. Washington, DC: American Psychological Association.

Ryan, R. M., Rigby, S., \& King, K. (1993). Two types of religious internalization and their relation to religious orientations and mental health. Journal of Personality and Social Psychology, 65, 586-596.

Salsman, J. M., Brown, T. L., Brechting, E. H., \& Carlson, C. R. (2005). The link between religion and spirituality and psychological adjustment: The mediating role of optimism and social support. Personality and Social Psychology Bulletin, 31, 522-535.

Skitka, L. J., Bauman, C. W., \& Mullen, E. (2004). Political tolerance and coming to psychological closure following the September 11, 2001 terrorist attacks: An integrative approach. Personality and Social Psychology Bulletin, 30, 743-756.

Smith, T. B., McCullough, M. E., \& Poll, J. (2003). Religiousness and depression: Evidence for a main effect and the moderating influence of stressful life events. Psychological Bulletin, 129, 614-636.

Solomon, S., Greenberg, J., \& Pyszczynski, T. (1991). A terror management theory of social behavior: The psychological functions of self-esteem and cultural worldviews. In M. P. Zanna (Ed.), Advances in experimental social psychology (Vol. 24, pp. 93-159). New York: Academic Press.

Towler, R. (1984). The need for certainty: A sociological study of conventional religion. London: Routledge \& Kegan Paul. 
Van den Bos, K. (2001). Uncertainty management: The influence of uncertainty salience on reactions to perceived procedural fairness. Journal of Personality and Social Psychology, 80, 931-941.

Van den Bos, K., Euwema, M. C., Poortvliet, P. M., \& Maas, M. (in press). Uncertainty management and social issues: Uncertainty as important determinant of reactions to socially deviating people. Journal of Applied Social Psychology.

Van den Bos, K., Heuven, E., Burger, E., \& Fernández Van Veldhuizen, M. (2006). Uncertainty management after reorganizations: The ameliorative effect of outcome fairness on job uncertainty. International Review of Social Psychology, 19, 75-86.
Van den Bos, K., \& Lind, E. A. (2002). Uncertainty management by means of fairness judgments. In M. P. Zanna (Ed.), Advances in experimental social psychology (Vol. 34, pp. 1-60). San Diego, CA: Academic Press.

Van den Bos, K., Poortvliet, P. M., Maas, M., Miedema, J., \& Van den Ham, E.-J. (2005). An enquiry concerning the principles of cultural norms and values: The impact of uncertainty and mortality salience on reactions to violations and bolstering of cultural worldviews. Journal of Experimental Social Psychology, 41, 91-113.

Watson, D., Clark, L. A., \& Tellegen, A. (1988). Development and validation of brief measures of positive and negative affect: The PANAS scales. Journal of Personality and Social Psychology, 54, 1063-1070. 